\title{
Microwave spectrum and the gas phase structure of phthalimide
}

Aaron M. Pejlovas ${ }^{\mathrm{a}}$, Wei Lin ${ }^{\mathrm{b}}$, Onur Oncer ${ }^{\mathrm{a}}$, and Stephen G. Kukolich ${ }^{\mathrm{a}}$

aDepartment of Chemistry and Biochemistry, University of Arizona, Tucson, AZ 85721

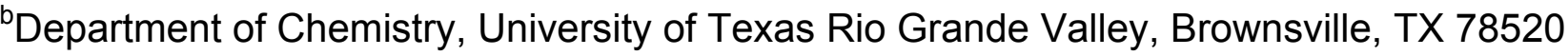

\section{Abstract}

The microwave spectrum of phthalimide $(\mathrm{Phl})$ was measured in the $4.8-9.5 \mathrm{GHz}$ range using a Flygare-Balle type, pulsed-beam Fourier transform microwave spectrometer. Rotational transitions were measured for the parent and all unique single ${ }^{13} \mathrm{C}$ substituted isotopologues. The rotational $(\mathrm{MHz})$, centrifugal distortion $(\mathrm{kHz})$, and quadrupole coupling constants $(\mathrm{MHz})$ were determined for the parent to be $A=1745.6655(10), B=1199.3309(6), C=711.0864(3), D_{J}=-0.012(7), D_{J K}=0.05(9)$, $1.5 X_{a a}=2.719(11)$, and $0.25\left(X_{b b^{-}} X_{c c}\right)=1.236(3)$. Using the measured rotational constants of the isotopologues, a nonlinear least squares fit was performed to obtain the best fit gas phase structure. The inertial defect is $=-0.175$ amu $\AA^{2}$, indicating a planar structure for $\mathrm{Phl}$.

Calculations using B3LYP/aug-cc-pVQZ provided rotational constants which are much closer to the experimental values compared to the MP2/6-311++G** calculated values. 
1. Introduction

Phthalimide (Phl) and its derivatives are important compounds, widely utilized in industry as well as in medicinal chemistry due to the biological activity of $\mathrm{Phl}$ and its derivatives. Synthesized derivatives of Phl used in medicinal chemistry have been found to have a wide range of biological activities, including antitumor, anti-inflammatory, and antimicrobial properties. ${ }^{1} \mathrm{Phl}$ derivatives are also used to interact with liver receptors that are involved in the regulation of cholesterol, lipid and glucose metabolism. ${ }^{2}$ In industry, $\mathrm{Phl}$ is used in plastics, plasticizers, and is also used in the synthesis of peptides and as a masked source for amines. ${ }^{3}$

Phthalimide, $\mathrm{C}_{6} \mathrm{H}_{4}(\mathrm{CO})_{2} \mathrm{NH}$, or isoindole-1,3-dione (IUPAC) has a melting point of $237-238{ }^{\circ} \mathrm{C}$. ${ }^{4} \mathrm{Phl}$ is a solid white crystal and can be obtained by heating phthalic anhydride with ammonia or another amine source, such as ammonium carbonate or ammonium acetate. ${ }^{5}$ The vapor pressure of $\mathrm{Phl}$ at $90^{\circ} \mathrm{C}$ is $\sim 0.01 \mathrm{Torr}^{6}$, sufficient to measure the rotational transitions using pulsed-beam Fourier transform (PBFT) microwave spectroscopy. The crystal structure of Phl was initially determined by Matzat ${ }^{7}$ using data collected from the mineral kladnoite. The IR spectrum was measured by Binev et al. ${ }^{8}$ and they also obtained structural parameters. In order to further refine the structure, Glidewell et al. performed an X-ray crystallography analysis on Phl that was crystallized with pyridine.$^{9}$ However, the $x$-ray structures are modified by packing effects and distortions, so it is also important to measure the pure rotational spectrum of $\mathrm{Phl}$ in an attempt obtain an accurate gas phase structure. 


\section{Microwave Measurements}

The phthalimide sample was purchased from Sigma Aldrich (99\%) and was used without further purification. A pulsedbeam Fourier transform microwave spectrometer, described previously, ${ }^{10,11}$ was used to make microwave measurements in the 4.8-9.5 GHz range for the parent isotopologue and these transitions are shown in Table 1. Ne was used as the carrier gas and the backing pressure was set to $\sim 1 \mathrm{~atm}$. Prior to the pulsed injection of the molecular sample, the pressure inside the microwave cavity was maintained at $10^{-6}$ to $10^{-7}$ Torr and the pulsed valve was heated to $\sim 125-130^{\circ} \mathrm{C}$ in order to obtain sufficient vapor pressure of the sample to obtain a parent test signal in one pulsed-beam cycle. The unique ${ }^{13} \mathrm{C}$ isotopologues of Phl were measured in the same way as the parent in the $4.8-6.5 \mathrm{GHz}$ range. The labeling scheme used to describe the isotopic substitutions is shown in Figure 1 and the measured rotational transitions for all the ${ }^{13} \mathrm{C}$ isotopologues are shown in Table 2.

\section{Calculations}

$A b$ initio calculations were performed using the GAUSSIAN-09 suite ${ }^{12}$ on the high performance computing system at the University of Arizona to obtain an optimized structure and predict the rotational transitions. Calculations were performed using MP $2^{13}$ and DFT (B3LYP) methods with $6-311++G^{* *}$ and aug-cc-pVQZ basis sets respectively. The calculated rotational and quadrupole coupling constants from each calculation were used in Pickett's SPCAT ${ }^{14}$ program to predict the rotational transitions of the parent isotopologue. 
In order to predict the rotational constants of all the unique ${ }^{13} \mathrm{C}$ isotopologues, first the ratios between the experimentally determined parent rotational constants and the MP2/6-311++G** calculated rotational constants were determined. After changing the mass of the ${ }^{13} \mathrm{C}$ atom within the calculated molecular structure and recalculating the rotational constants of the new structure, these rotational constants for each isotopologue were multiplied by the previously determined experimental/calculated ratio to obtain corrected rotational constants of the ${ }^{13} \mathrm{C}$ isotopologues. These corrected values were within $<1 \%$ of the final experimentally fit values. These corrected rotational constants and the quadrupole coupling constants of the parent were used in the SPCAT program to predict the ${ }^{13} \mathrm{C}$ isotopologue rotational transitions.

\section{Rotational Constants}

The rotational constants for the parent and all unique ${ }^{13} \mathrm{C}$ isotopologues were determined using Pickett's SPFIT ${ }^{14}$ program and these results are shown in Table 3. While fitting the measured rotational transitions of the unique ${ }^{13} \mathrm{C}$ isotopologues, the centrifugal distortion constants $\left(D_{J}\right.$ and $\left.D_{J K}\right)$ were held fixed to values obtained from the fit for the parent. The rotational constants obtained from the best fit gas phase structure are shown with the experimentally fit rotational constants of all the isotopologues and the measured - calculated differences $(M-C)$ of these values are listed in Table 4. Differences between the calculated rotational constants of the best fit structure and its isotopologues had a standard deviation of $0.14 \mathrm{MHz}$. The B3LYP/aug-cc-pVQZ calculated rotational constants were much closer to the experimentally determined values compared to the MP2/6-311++G** values, and this can also be seen in Table 3. 


\section{Molecular Structure}

To obtain a best fit gas phase structure of the Phl molecule, a nonlinear least squares fit was performed using the measured rotational constants from each of the isotopologues. In the least squares fit, there were a total of 8 varied parameters in 2D Cartesian space (the plane of the molecule). From the B3LYP/aug-cc-pVQZ calculation, the structure of Phl was determined to be planar with $\mathrm{C}_{2 v}$ symmetry and this substantially reduced the number of parameters in the fit. Due to the planar structure the coordinates for the $\mathrm{Phl}$ molecule were restricted to the $\mathrm{x}-\mathrm{y}$ plane ( same as the a-b plane). The inertial defect obtained from the experimental rotational constants of the parent isotopologue is $=-0.175 \mathrm{amu} \AA^{2}$, confirming that the structure of $\mathrm{Phl}$ is indeed planar since this experimental value is close to zero. The small negative nonzero value however indicates the presence of out of plane vibrations within the molecule. ${ }^{15}$

The variable parameters are the $x-y$ coordinates of the 4 unique carbon atoms $(C 1, C 5, C 6$ and $C 7)$ relative to the $N$ atom location. These are the 8 variable fit parameters. During this structure fit, the $\mathrm{x}-\mathrm{y}$ coordinates of $\mathrm{H}$ and $\mathrm{O}$ atoms are fixed relative to the bonded carbon or nitrogen atom using the Gaussian calculated values for these parameters. So it is really only the inner skeleton of the molecule which is adjusted. The center of mass (COM) is recalculated on each iteration of the fit. Due to the $\mathrm{C}_{2 v}$ symmetry in the molecule, coordinates for each corresponding atom on opposite sides of the symmetry axis (a-axis) were varied using the same magnitude of the variable $x$ and $y$ parameters, with reversed signs for the $y$-parameters. With these constraints and variable parameters set, the structure fit produced a very good "best fit" structure with a standard deviation of only $0.14 \mathrm{MHz}$. Since the fixed parameters from the calculations are equilibrium values $\left(r_{e}\right)$ and parameters fitted to the 
rotational constants will be vibrationally averaged $\left(r_{0}\right)$ parameters the result is really structure with mixed $r_{e}$ and $r_{0}$ coordinates. We believe that the differences are small so that this is a reasonably accurate representation of the ground state vibrationally averaged structure for the molecule. The most significant errors will be for the $\mathrm{C}-\mathrm{H}$ bond lengths.

A Kraitchman analysis was performed for all the ${ }^{13} \mathrm{C}$ isotopologues using the Kisiel KRA ${ }^{16}$ program. The best fit structure coordinates of the parent are compared to the ${ }^{13} \mathrm{C}$ coordinates determined by the Kraitchman analysis in Table 5 . The Kraitchman analysis only provides the magnitudes of coordinates relative to the center of mass of the parent, so only the magnitudes can be compared. The agreement between the magnitudes of the Kraitchman coordinates and best fit structure coordinates is very good, with the exception of the a-coordinate of $\mathrm{C} 1$ which is different by $\sim 0.04 \AA$. C 1 is closer to the center of mass, so the Kraitchman coordinates will be less reliable.

The structural parameters obtained from the structure fit are shown in Table 6 (bond lengths) and Table 7 (angles) with comparisons to the B3LYP/aug-cc-pVQZ calculated values. These bond lengths and angles correspond to those shown in Figure 1. Because of the $\mathrm{C}_{2 v}$ symmetry of Phl, only the bond lengths and angles for one side of the symmetry axis are shown. The fit bond lengths and angles compared to the B3LYP calculation are very close, only differing by $\sim 0.005 \AA$ for the bond lengths and are equal for all angles, with the exception of $<\left(\mathrm{C}_{1}-\mathrm{C}_{2}-\mathrm{C}_{3}\right)$ which is increased by $1^{\circ}$ from the calculated value. 


\section{Discussion}

The rotational spectrum of $\mathrm{Phl}$ was measured in the 4.8 to $9.5 \mathrm{GHz}$ range using pulsed-beam Fourier transform microwave spectroscopy. The rotational transitions measured for the parent and all unique ${ }^{13} \mathrm{C}$ isotopologues are given in Tables 1 and 2. Using the rotational constants determined from each of the measured isotopologues, a partial gas phase structure was determined and is shown in Figure 1. Tables $5-7$ show the best fit a and b coordinates in the principal axis system, the interatomic distances, and interbond bond angles, respectively. The best fit structure obtained of $\mathrm{Phl}$ is in very good agreement with the crystal structure data obtained previously, ${ }^{7}$ with the bond lengths only deviating by $\sim 0.01 \AA$ and angles varying by $\sim 0.1^{\circ}$. The reported structure is a mix of equilibrium and ground state averaged structures, but we believe the differences are small so the derived structure is reasonable representation of the ground state. Obtaining a more complete gas phase structure would require the measurement of deuterium substituted isotopologues.

\section{$\underline{\text { Acknowledgements }}$}

This material is based upon work supported by the National Science Foundation under Grant No. CHE-1057796 at the University of Arizona. Wei Lin Thanks the Welch Foundation for financial support. We are extremely grateful to the reviewer for pointing out serious errors in a previous version of this paper 
Figure 1. The structure of phthalimide obtained by fitting the measured rotational constants for all measured isotopologues.

The top section shows bond lengths (top, in $\AA$ ) and bottom shows interbond angles (bottom, in ${ }^{\circ}$ ). Also shown are the directions of the $a$ and $b$ principle axes for the molecule.

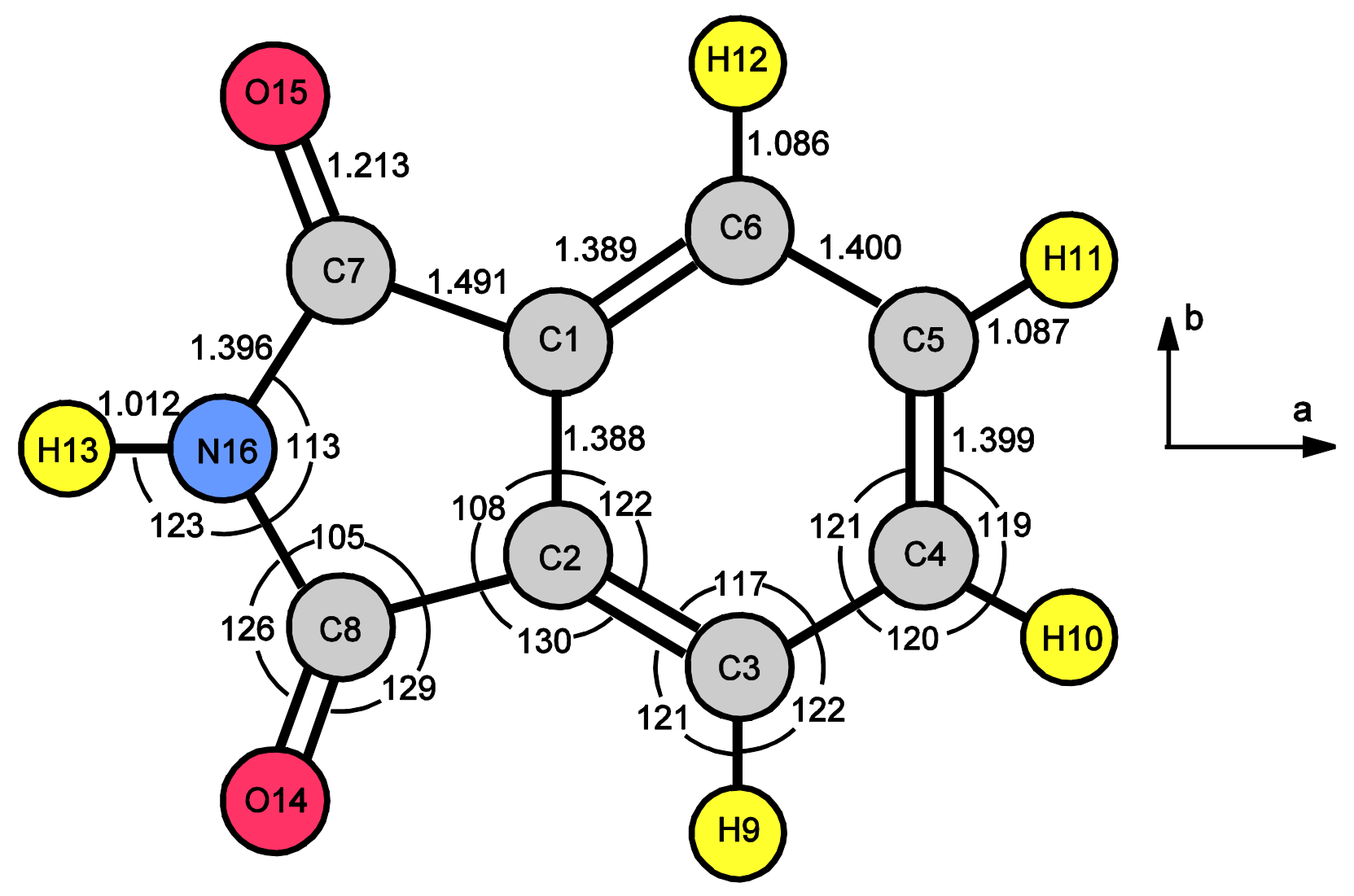


Table 1. Measured rotational transitions ( $v_{\mathrm{obs}}$ ) of the parent isotopologue shown in $\mathrm{MHz}$ and deviations of the best fit calculated frequencies from the observed values $\left(v_{0-c}\right)$.

\begin{tabular}{|c|c|c|c|}
\hline$J^{\prime} K a^{\prime} K c^{\prime} F$ & J" Ka" Kc" F" & $v_{\text {obs }}$ & $v_{0}$ \\
\hline 3134 & 21223 & 4885.647 & -0.001 \\
\hline $\begin{array}{llll}3 & 1 & 3 & 2\end{array}$ & $\begin{array}{llll}2 & 1 & 2 & 1\end{array}$ & 4885.773 & 0.002 \\
\hline $\begin{array}{llll}3 & 1 & 3 & 3\end{array}$ & 2122 & 4885.932 & -0.004 \\
\hline $\begin{array}{llll}3 & 1 & 3 & 3\end{array}$ & $\begin{array}{llll}2 & 1 & 2 & 3\end{array}$ & 4887.012 & -0.002 \\
\hline $\begin{array}{llll}3 & 0 & 3 & 2\end{array}$ & 2022 & 5057.851 & -0.004 \\
\hline $\begin{array}{llll}3 & 0 & 3 & 4\end{array}$ & $\begin{array}{llll}2 & 0 & 2 & 3\end{array}$ & 5059.259 & -0.002 \\
\hline $\begin{array}{lll}3 & 0 & 32\end{array}$ & 2021 & 5059.336 & 0.008 \\
\hline $\begin{array}{llll}3 & 0 & 3 & 3\end{array}$ & 2022 & 5059.637 & 0.010 \\
\hline $\begin{array}{llll}3 & 0 & 3 & 3\end{array}$ & $\begin{array}{llll}2 & 0 & 2 & 3\end{array}$ & 5060.568 & -0.005 \\
\hline 4234 & 4044 & 5076.449 & -0.003 \\
\hline 4235 & $\begin{array}{llll}4 & 0 & 4 & 5\end{array}$ & 5077.656 & -0.005 \\
\hline 4233 & $\begin{array}{llll}4 & 0 & 4 & 3\end{array}$ & 5077.972 & 0.000 \\
\hline 3222 & $\begin{array}{llll}2 & 2 & 1 & 1\end{array}$ & 5730.793 & -0.006 \\
\hline 3224 & 2213 & 5731.123 & 0.000 \\
\hline 3223 & 2213 & 5731.123 & 0.000 \\
\hline $\begin{array}{lll}3223 \\
\end{array}$ & 2212 & 5731.703 & -0.002 \\
\hline 3222 & 2212 & 5731.703 & -0.002 \\
\hline $\begin{array}{lll}3 & 1 & 22\end{array}$ & $\begin{array}{llll}2 & 1 & 1 & 1\end{array}$ & 6285.845 & -0.002 \\
\hline 3124 & 21113 & 6286.060 & 0.000 \\
\hline $\begin{array}{lll}3 & 1 & 2\end{array}$ & $\begin{array}{llll}2 & 1 & 1 & 2\end{array}$ & 6286.374 & 0.002 \\
\hline 4145 & $\begin{array}{llll}3 & 1 & 3 & 4\end{array}$ & 6368.981 & -0.005 \\
\hline 4143 & $\begin{array}{llll}3 & 1 & 3 & 2\end{array}$ & 6369.065 & 0.002 \\
\hline 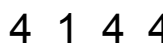 & $\begin{array}{llll}3 & 1 & 3 & 3\end{array}$ & 6369.185 & 0.003 \\
\hline $\begin{array}{llll}3 & 2 & 1 & 2\end{array}$ & $\begin{array}{llll}2 & 2 & 0 & 1\end{array}$ & 6402.812 & -0.000 \\
\hline 3214 & 2203 & 6403.096 & 0.005 \\
\hline $\begin{array}{llll}32 & 13\end{array}$ & 2202 & 6403.328 & -0.002 \\
\hline 4045 & $\begin{array}{llll}3 & 0 & 3 & 4\end{array}$ & 6437.139 & -0.004 \\
\hline
\end{tabular}




\begin{tabular}{|rrrrrrrrrrr}
4 & 0 & 4 & 3 & 3 & 0 & 3 & 2 & & 6437.206 & 0.003 \\
4 & 0 & 4 & 4 & 3 & 0 & 3 & 3 & & 6437.383 & -0.002 \\
2 & 2 & 0 & 1 & 1 & 0 & 1 & 1 & & 7194.918 & 0.001 \\
2 & 2 & 0 & 3 & 1 & 0 & 1 & 2 & & 7194.940 & 0.005 \\
4 & 2 & 3 & 3 & 3 & 2 & 2 & 2 & & 7468.723 & 0.008 \\
4 & 2 & 3 & 3 & 3 & 2 & 2 & 3 & & 7468.723 & 0.008 \\
4 & 2 & 3 & 5 & 3 & 2 & 2 & 4 & & 7468.799 & -0.005 \\
4 & 2 & 3 & 4 & 3 & 2 & 2 & 3 & & 7469.146 & -0.003 \\
4 & 2 & 3 & 4 & 3 & 2 & 2 & 4 & & 7469.146 & -0.003 \\
5 & 1 & 5 & 6 & 4 & 1 & 4 & 5 & & 7813.517 & -0.002 \\
5 & 1 & 5 & 4 & 4 & 1 & 4 & 3 & & 7813.568 & -0.005 \\
5 & 1 & 5 & 5 & 4 & 1 & 4 & 4 & & 7813.672 & 0.009 \\
5 & 0 & 5 & 6 & 4 & 0 & 4 & 5 & & 7834.351 & 0.000 \\
5 & 0 & 5 & 4 & 4 & 0 & 4 & 3 & & 7834.396 & -0.005 \\
5 & 0 & 5 & 5 & 4 & 0 & 4 & 4 & & 7834.499 & -0.010 \\
4 & 1 & 3 & 3 & 3 & 1 & 2 & 2 & & 7993.887 & 0.005 \\
4 & 1 & 3 & 3 & 3 & 1 & 2 & 4 & & 7993.953 & 0.003 \\
4 & 1 & 3 & 5 & 3 & 1 & 2 & 4 & & 7993.988 & -0.005 \\
4 & 1 & 3 & 4 & 3 & 1 & 2 & 3 & & 7994.350 & -0.004 \\
5 & 2 & 4 & 4 & 4 & 2 & 3 & 3 & & 9088.837 & 0.009 \\
5 & 2 & 4 & 6 & 4 & 2 & 3 & 5 & & 9088.871 & 0.007 \\
5 & 2 & 4 & 5 & 4 & 2 & 3 & 4 & & 9089.131 & -0.000 \\
6 & 1 & 6 & 7 & 5 & 1 & 5 & 6 & & 9242.336 & -0.000 \\
6 & 1 & 6 & 5 & 5 & 1 & 5 & 4 & & 9242.377 & -0.001 \\
6 & 1 & 6 & 6 & 5 & 1 & 5 & 5 & & 9242.445 & -0.000 \\
6 & 0 & 6 & 7 & 5 & 0 & 5 & 6 & & 9247.940 & 0.003 \\
6 & 0 & 6 & 5 & 5 & 0 & 5 & 4 & & 9247.975 & -0.003 \\
6 & 0 & 6 & 6 & 5 & 0 & 5 & 5 & & 9248.051 & 0.002 \\
\hline
\end{tabular}


Table 2. Measured rotational transitions of each unique ${ }^{13} \mathrm{C}$ isotopologue shown in $\mathrm{MHz}$.

\begin{tabular}{|c|c|c|c|c|c|c|c|c|c|}
\hline \multicolumn{2}{|c|}{ Rotational Transitions } & \multicolumn{2}{|r|}{${ }^{13} \mathrm{C} 1 \& 2$} & \multicolumn{2}{|c|}{${ }^{13} \mathrm{C} 3 \& 6$} & \multicolumn{2}{|r|}{${ }^{13} \mathrm{C} 4 \& 5$} & \multicolumn{2}{|r|}{${ }^{13} \mathrm{C} 7 \& 8$} \\
\hline $\mathrm{J}^{\prime} \mathrm{Ka}^{\prime} \mathrm{Kc} \mathrm{c}^{\prime} \mathrm{F}^{\prime}$ & J" Ka" Kc" F" & $v_{\mathrm{obs}}$ & $v_{\mathrm{O}-\mathrm{C}}$ & $v_{\mathrm{obs}}$ & $v_{\mathrm{O}-\mathrm{C}}$ & $v_{\mathrm{obs}}$ & $v_{\mathrm{O}-\mathrm{C}}$ & $v_{\text {obs }}$ & $v_{\mathrm{O}-\mathrm{c}}$ \\
\hline $\begin{array}{llll}3 & 1 & 3 & 4\end{array}$ & 2123 & 4882.766 & 0.001 & 4859.367 & 0.001 & 4831.116 & 0.001 & 4867.167 & 0.001 \\
\hline $\begin{array}{llll}3 & 1 & 3 & 2\end{array}$ & 2121 & 4882.887 & 0.000 & 4859.490 & 0.003 & 4831.235 & -0.002 & 4867.290 & 0.000 \\
\hline $\begin{array}{llll}3 & 1 & 3 & 3\end{array}$ & 2122 & 4883.056 & -0.004 & 4859.655 & -0.005 & 4831.403 & -0.001 & 4867.456 & -0.004 \\
\hline $\begin{array}{llll}3 & 0 & 3 & 4\end{array}$ & 2023 & 5055.325 & -0.002 & 5030.741 & -0.004 & 5011.206 & 0.000 & 5039.398 & -0.001 \\
\hline $\begin{array}{llll}3 & 0 & 3 & 2\end{array}$ & 20021 & 5055.406 & 0.005 & 5030.821 & 0.003 & 5011.273 & -0.000 & 5039.472 & 0.004 \\
\hline $\begin{array}{llll}3 & 0 & 3 & 3\end{array}$ & 2022 & 5055.692 & 0.001 & 5031.106 & 0.001 & 5011.570 & 0.001 & 5039.767 & -0.001 \\
\hline 4145 & $\begin{array}{llll}3 & 1 & 3 & 4\end{array}$ & 6364.763 & -0.002 & 6334.076 & -0.006 & 6302.040 & -0.005 & 6344.535 & -0.003 \\
\hline 4143 & $\begin{array}{llll}3 & 1 & 3 & 2\end{array}$ & 6364.848 & 0.002 & 6334.165 & 0.005 & 6302.129 & 0.007 & 6344.619 & 0.003 \\
\hline 4144 & $\begin{array}{llll}3 & 1 & 3\end{array}$ & 6364.964 & -0.003 & 6334.282 & 0.002 & 6302.241 & -0.000 & 6344.740 & 0.003 \\
\hline 4045 & $\begin{array}{llll}3 & 0 & 3 & 4\end{array}$ & 6432.188 & -0.004 & 6400.922 & -0.001 & 6375.781 & -0.000 & 6411.909 & 0.000 \\
\hline $\begin{array}{llll}4 & 0 & 4 & 3\end{array}$ & $\begin{array}{llll}3 & 0 & 3 & 2\end{array}$ & 6432.255 & 0.003 & 6400.988 & 0.003 & 6375.841 & 0.000 & 6411.965 & -0.005 \\
\hline 4044 & $\begin{array}{llll}3 & 0 & 3 & 3\end{array}$ & 6432.426 & 0.003 & 6401.160 & -0.002 & 6376.023 & -0.002 & 6412.155 & 0.003 \\
\hline
\end{tabular}

Table 3. Best fit rotational constants, centrifugal distortion and quadrupole coupling constants of the parent and unique ${ }^{13} \mathrm{C}$ isotopologues, as well as the MP2/6-311++G** calculated values for the parent.

\begin{tabular}{|c|c|c|c|c|c|c|c|}
\hline & Parent & $\begin{array}{r}\mathrm{MP2/6-} \\
311++\mathrm{G}^{* *}\end{array}$ & $\begin{array}{r}\text { B3LYP/aug-cc- } \\
\text { pVQZ }\end{array}$ & ${ }^{13} \mathrm{C}(1 \& 2)$ & ${ }^{13} \mathrm{C}(3 \& 6)$ & ${ }^{13} \mathrm{C}(4 \& 5)$ & ${ }^{13} \mathrm{C}(7 \& 8)$ \\
\hline$A / \mathrm{MHz}$ & $1745.6655(10)$ & 1731.668 & 1753.935 & $1742.783(12)$ & $1733.751(12)$ & $1742.887(12)$ & $1737.654(12)$ \\
\hline$B / \mathrm{MHz}$ & $1199.33090(57)$ & 1194.126 & 1202.057 & 1199.2423(68) & 1193.7412(68) & $1180.4406(6)$ & $1195.2699(68)$ \\
\hline $\mathrm{C} / \mathrm{MHZ}$ & 711.08644(31) & 706.758 & 713.239 & $710.5795(14)$ & $707.13820(135)$ & $703.9465(13)$ & 708.3290(14) \\
\hline$D_{J} / \mathrm{kHz}$ & $-0.0120(69)$ & & & $-0.0120^{*}$ & $-0.0120^{*}$ & $-0.0120^{*}$ & $-0.0120^{*}$ \\
\hline$D_{J K} / \mathrm{kHz}$ & $0.050(86)$ & & & $0.050^{*}$ & $0.050 *$ & $0.050^{*}$ & $0.050 *$ \\
\hline $1.5 X_{a a} / \mathrm{MHz}$ & $2.719(11)$ & 2.9207 & 2.9480 & $2.875(86)$ & $2.856(86)$ & $2.785(86)$ & $2.790(86)$ \\
\hline $0.25\left(X_{b b^{-}} X_{c c}\right) / \mathrm{MHz}$ & $1.2363(39)$ & 1.2916 & 1.2745 & $1.222(15)$ & $1.222(15)$ & $1.231(15)$ & $1.248(15)$ \\
\hline $\mathrm{N}$ & 55 & & & 12 & 12 & 12 & 12 \\
\hline$\sigma / k H z$ & 4 & & & 3 & 3 & 3 & 3 \\
\hline
\end{tabular}

${ }^{*}$ Centrifugal distortion constants were held fixed to the parent during fits of ${ }^{13} \mathrm{C}$ isotopologues 
Table 4. Measured rotational constants $(\mathrm{MHz})$ compared with the rotational constants calculated of the best fit structure, also showing the difference $(M-C)$.

\begin{tabular}{|crrrr|}
\hline \multicolumn{2}{|c}{ ISOTOPOLOGUE } & MEASURED & CALCULATED & $(\mathrm{M}-\mathrm{C})$ \\
\hline Parent & $\mathrm{A}$ & 1745.6654 & 1745.6989 & -0.0334 \\
& $\mathrm{~B}$ & 1199.3309 & 1199.4121 & -0.0812 \\
& $\mathrm{C}$ & 711.0864 & 710.9451 & 0.1413 \\
${ }^{13} \mathrm{C} 1 \& 2$ & $\mathrm{~A}$ & 1742.7830 & 1742.8085 & -0.0255 \\
& $\mathrm{~B}$ & 1199.2423 & 1199.2756 & -0.0333 \\
& $\mathrm{C}$ & 710.5795 & 710.4174 & 0.1621 \\
${ }^{13} \mathrm{C} 3 \& 6$ & $\mathrm{~A}$ & 1733.7512 & 1733.7742 & -0.0230 \\
& $\mathrm{~B}$ & 1193.7412 & 1193.7870 & -0.0458 \\
& $\mathrm{C}$ & 707.1382 & 706.9902 & 0.1480 \\
${ }^{13} \mathrm{C} 4 \& 5$ & $\mathrm{~A}$ & 1742.8865 & 1742.9089 & -0.0224 \\
& $\mathrm{~B}$ & 1180.4406 & 1180.4885 & -0.0479 \\
& $\mathrm{C}$ & 703.9465 & 703.7989 & 0.1476 \\
${ }^{13} \mathrm{C} 7 \& 8$ & $\mathrm{~A}$ & 1737.6542 & 1737.6740 & -0.0198 \\
& $\mathrm{~B}$ & 1195.2699 & 1195.3256 & -0.0557 \\
& $\mathrm{C}$ & 708.3290 & 708.1781 & 0.1509 \\
\hline \hline
\end{tabular}

Table 5. The a and b coordinates $(\AA)$ of the atoms in the principle inertial axis system obtained from the structure fit (columns 2 and 3). Columns 4 and 5 give the absolute values of $a$ and $b$ atomic coordinates obtained from the Kraitchman analysis (Krait-a and Krait-b). Please note that only absolute values of these coordintates are obtained from the Kraitchman analysis. 


\begin{tabular}{rrrrr}
\hline \multicolumn{1}{c}{ Atom } & \multicolumn{1}{l}{ a } & \multicolumn{1}{l}{ Krait-a } & \multicolumn{1}{c}{ Krait-b } \\
\hline C1 & -0.2190 & 0.6942 & $( \pm) 0.168(12)$ & $( \pm) 0.6932(26)$ \\
C2 & -0.2190 & -0.6943 & $( \pm) 0.168(12)$ & $( \pm) 0.6932(26)$ \\
C3 & -1.4008 & -1.4241 & $( \pm) 1.3984(27)$ & $( \pm) 1.4235(27)$ \\
C4 & -2.5988 & -0.6992 & $( \pm) 2.59741(74)$ & $( \pm) 0.6978(26)$ \\
C5 & -2.5988 & 0.6994 & $( \pm) 2.59741(74)$ & $( \pm) 0.6978(26)$ \\
C6 & -1.4007 & 1.4242 & $( \pm) 1.3984(27)$ & $( \pm) 1.4235(27)$ \\
C7 & 1.1962 & 1.1646 & $( \pm) 1.1926(16)$ & $( \pm) 1.1636(16)$ \\
C8 & 1.1961 & -1.1647 & $( \pm) 1.1926(16)$ & $( \pm) 1.1636(16)$ \\
H9 & -1.389 & -2.510 & & \\
H10 & -3.547 & -1.231 & & \\
H11 & -3.547 & 1.231 & & \\
H12 & -1.389 & 2.511 & & \\
H13 & 2.978 & -0.000 & & \\
O14 & 1.624 & -2.300 & & \\
O15 & 1.624 & 2.300 & & \\
N16 & 1.966 & 0.000 & & \\
\hline
\end{tabular}


Table 6. Microwave fit values for bond lengths $(\AA)$ compared to B3LYP/aug-cc-pVQZ calculated values.

\begin{tabular}{|rrr|}
\hline Interatomic Distance & $\begin{array}{r}\text { Microwave Fit Value } \\
(\AA)\end{array}$ & $\begin{array}{r}\text { Calculated } \\
\text { Value }(\AA)\end{array}$ \\
\hline $\mathrm{r}\left(\mathrm{C}_{1}-\mathrm{C}_{2}\right)$ & 1.388 & 1.392 \\
$\mathrm{r}\left(\mathrm{C}_{1}-\mathrm{C}_{6}\right)$ & 1.389 & 1.381 \\
$\mathrm{r}\left(\mathrm{C}_{1}-\mathrm{C}_{7}\right)$ & 1.491 & 1.493 \\
$\mathrm{r}\left(\mathrm{C}_{7}-\mathrm{N}_{16}\right)$ & 1.396 & 1.398 \\
$\mathrm{r}\left(\mathrm{C}_{5}-\mathrm{C}_{6}\right)$ & 1.400 & 1.395 \\
$\mathrm{r}\left(\mathrm{C}_{4}-\mathrm{C}_{5}\right)$ & 1.399 & 1.394 \\
\hline
\end{tabular}

Table 7. Microwave fit values for angles (in degrees) compared to B3LYP/aug-cc-pVQZ calculated values.

\begin{tabular}{||rrr|}
\hline Angle & Microwave Fit Value & Calculated \\
\hline$<\left(\mathrm{C}_{1}-\mathrm{C}_{2}-\mathrm{C}_{3}\right)$ & 122 & 121 \\
$<\left(\mathrm{C}_{1}-\mathrm{C}_{2}-\mathrm{C}_{8}\right)$ & 108 & 108 \\
$<\left(\mathrm{C}_{3}-\mathrm{C}_{2}-\mathrm{C}_{8}\right)$ & 130 & 130 \\
$<\left(\mathrm{N}_{16}-\mathrm{C}_{8}-\mathrm{C}_{2}\right)$ & 105 & 105 \\
$<\left(\mathrm{N}_{16}-\mathrm{C}_{8}-\mathrm{O}_{14}\right)$ & 126 & 126 \\
$<\left(\mathrm{C}_{2}-\mathrm{C}_{8}-\mathrm{O}_{14}\right)$ & 129 & 129 \\
$<\left(\mathrm{C}_{7}-\mathrm{N}_{16}-\mathrm{C}_{8}\right)$ & 113 & 113 \\
$<\left(\mathrm{H}_{13}-\mathrm{N}_{16}-\mathrm{C}_{8}\right)$ & 123 & 123 \\
$<\left(\mathrm{C}_{2}-\mathrm{C}_{3}-\mathrm{C}_{4}\right)$ & 117 & 117 \\
$<\left(\mathrm{C}_{2}-\mathrm{C}_{3}-\mathrm{H}_{9}\right)$ & 121 & 121 \\
$<\left(\mathrm{H}_{9}-\mathrm{C}_{3}-\mathrm{C}_{4}\right)$ & 122 & 122 \\
$<\left(\mathrm{C}_{5}-\mathrm{C}_{4}-\mathrm{C}_{3}\right)$ & 121 & 121 \\
$<\left(\mathrm{C}_{5}-\mathrm{C}_{4}-\mathrm{H}_{10}\right)$ & 119 & 119 \\
$<\left(\mathrm{H}_{10}-\mathrm{C}_{4}-\mathrm{C}_{3}\right)$ & 120 & 120 \\
\hline
\end{tabular}

${ }^{1}$ M.A. Motaleb, L.Y. Abdel-Ghaney, H.M. Abdel-Bary, H.A. Shamsel-Din. J. Radioanal. Nucl. Chem. DOI 10.1007/s10967-015-4140-3. May 8, 2015.

${ }^{2}$ Kishida, K. Aoyama, A. Hasimoto, Y. Miyachi, H. Chem. Pharm. Bull. 58. (11). (2010). 15251528. 
${ }^{3}$ T. W. Green, P. G. M. Wuts, "Protective Groups in Organic Synthesis," WileyInterscience,New York, 1999, 564-566, 740-743.

${ }^{4}$ L.J. Winters and W.E. McEwen. Reactions of 2-Bromo-2,2-dinitroethyl acetate with Bases. Tetrahedron. (1963). 19. 49-56.

${ }^{5}$ W. A. Noyes and P. K. Porter, Org. Syn., 2, 75 (1922)

${ }^{6}$ M.A.V. Ribeiro da Silva. Claudia P.F. Santos. M.J.S. Monte. C.A.D. Sousa. Thermochemical studies of phthalimide and two $\mathrm{N}$-alkylsubstituted phthalimides (alkyl=ethyl and n-propyl). J.

Therm. Anal. Cal. (2006). 83. 533-539.

${ }^{7}$ Matzat, E. (1972). Acta Cryst. B28, 415-418.

${ }^{8}$ Binev, I.G. Stamboliyska, B.A. Binev, Y.I. Velcheva, E.A. Tsenov, J.A. Journal of Molecular Structure. 513 (1999) 231-243.

${ }^{9}$ Choudhury M. Zakaria. John N. Low. Christopher Glidewell. Phthalimide at $120 \mathrm{~K}$ : perforated molecular ribbons containing three different ring motifs. Acta. Cryst. (2002). C58. o9-010.

${ }^{10}$ R. E. Bumgarner and S. G. Kukolich, J. Chem Phys. 86, 1083 (1987).

${ }^{11}$ B. S. Tackett, C. Karunatilaka, A. M. Daly, and S. G. Kukolich, Organometallics 26(8), 20702076 (2007).http://dx.doi.org/10.1021/om061027f

${ }^{12}$ M.J. Frisch, et al. Gaussian 09, Revision A.1, Gaussian, Inc., Wallingford, CT (2009)

${ }^{13}$ C. Moller, M.S. Plesset, Phys. Rev., 46 (1934), p. 618

${ }^{14}$ H.M. Pickett, J. Mol. Spectrosc. 148 (1991) 371.

http://spec.jpl.nasa.gov/ftp/pub/calpgm/spinv.html

${ }^{15}$ T. Oka. Journal of Molecular Structure 352/353 (1995) 225-233

${ }^{16}$ Z. Kisiel , <http://www.ifpan.edu.pl/ kisiel/struct/struct.htm\#kra> 